\title{
Prospect Theory and Stock Returns: A Seven Factor Pricing Model.
}

\begin{abstract}
The single-factor Capital Asset Pricing Model (CAPM), and its multi-factor extensions, are models that seek to explain investor's expectations for returns on risky assets. Empirical studies however, show that these factor models do not fully explain variations in expected returns. We show that a simple two factor model, based on the Peak-end rule (Fredrickson and Kahneman, 1993) from Prospect Theory (Kahneman and Tversky, 1979, 1992) explains variations in asset returns more thoroughly than the CAPM or it's extensions. Our results are derived from an extensive study on all US listed securities over the time period of 1927-2014. Based on our findings, we propose a Seven-Factor asset pricing model merging the insights of Expected Utility Theory, and Prospect Theory. Our new model explains variations in asset returns more comprehensively than the CAPM and its extensions including the recently established five factor CAPM by Fama and French (2015).
\end{abstract}

Key Words: Prospect Theory, Peak-end rule, Cognitive bias, CAPM.

JEL Classification: G10, G11, G12 


\section{Introduction}

The Capital Asset Pricing Model (CAPM) (Treynor, 1961; Sharpe, 1963, 1964) has been a dominant paradigm for pricing risky assets in financial markets since the early nineteen-sixties. Numerous authors such as Mossin (1966), Lintner (1965, 1969), Black (1972), Merton (1973), Ross (1976), Fama and French (1993), Carhart (1997), and Fama and French (2015) amongst many others have extended and generalised the CAPM. Notwithstanding the development of more recent approaches, the CAPM is still a key metric for finance industry professionals, because of the model's simplicity, parsimonious nature, and functionality in many contexts. Modern Portfolio Theory (MPT) (Markowitz, 1952), explains any individual investor's optimal portfolio selection, representing a market in partial equilibrium. The CAPM extends this by providing a general equilibrium model that explains all investor's expectations for returns on risky assets. An important underlying assumption in the CAPM and the other aforementioned models is that investors are rational, risk-averse, end-of-period utility maximisers. Thus, the above approaches to asset pricing are based on the use of utility theory to form expectations on future end-of-period returns.

Meanwhile, alternative approaches to explaining financial decision-making, market prices, and returns, have emerged in parallel to the above developments. These do not invoke assumptions of rational agents, or expected utility theory. Collectively referred to as "behavioural finance", they rely instead on behavioural or cognitive models of decision-making under risk, and build on insights from psychology, neuroscience, and other fields. An increasing number of papers in behavioural finance have appeared in scholarly journals in recent years ${ }^{1}$. The principal topics of

\footnotetext{
${ }^{1}$ See Subrahmanyam (2008), and Thaler (2005) for surveys.
} 
behavioural finance include; the concepts of heuristics: That agents make decisions using pragmatic criteria based on cognitive biases, rather than rational analysis and market inefficiencies: That violations of the efficient market hypothesis (EMH) or mis-pricing, arise from non-rational decision-making. Moreover, Aronson (2006) points out that the theory of behavioural finance blends with the practice of technical analysis, stating that "By considering the impact of emotions, cognitive errors, irrational preferences, and the dynamics of group behaviour, behavioural finance offers succinct explanations of excess market volatility as well as the excess returns earned by stale information strategies.... cognitive errors may also explain the existence of market inefficiencies that spawn the systematic price movements that allow objective TA [technical analysis] methods to work". A seminal theory in behavioural economics, and its sub-field behavioural finance, is Prospect Theory (Kahneman and Tversky, 1979; Tversky and Kahneman, 1992). This holds that agents evaluate decisions under risk using a set of psychological criteria. This theory has become one of the most important descriptive alternatives to expected utility theory. There are four elements of Prospect theory, including reference dependence, loss aversion, diminishing sensitivity, and probability weighting. An important testable proposition of the theory, with implications for asset pricing and market efficiency, is that one of these criteria is Reference Dependence; In evaluating expected outcomes agents use a "reference value", to which actual outcomes are subsequently compared, and classified as "gains" if greater than the reference value, and "losses" if less than the reference value.

The best-known example of Reference Dependence is the peak-end rule (Fredrickson and Kahneman, 1993). The peak-end model fits experiences that have a defined beginning and end. It holds that agents judge an experience or event by how they felt at its peak and end rather than by the sum total, or the average of every moment of an event. Other information, aside from that of 
the peak and end of the experience, is not lost but is not used, according to the theory. In a financial market context, for an investor assessing expected end of period returns (e.g. monthly returns), this cognitive model has a natural interpretation. The peak returns and end of period returns for the previous period should have significant explanatory power for the expected end of period returns for the following period. Additional data, such as the cumulative return over the period, the average return, or other explanatory factors are disregarded. Thus, they should have less explanatory power. The peak-end model is also consistent with popular indicators used in technical analysis, such as support levels, resistance levels, and channels, and may help explain the apparent success of technical trading strategies reported by several academic studies. ${ }^{2}$

In this paper, we aim to study the asset pricing performance when applying the Peak-End rule to Prospect Theory. We examine whether empirical expected stock returns can be improved by extending the previous asset pricing models to capture Prospect theory estimated via the Peak-End rule. In particular, we add PEAK and END variables to asset pricing models to test if they can help to explain the cross-sectional return of stocks. The PEAK variable is defined as the monthly excess return for portfolio $i$ implied by the highest daily return occurring in the previous month. The END variable is the monthly excess return for portfolio $i$ for the previous month. According to the Reference Dependence component of Prospect Theory, the value function depends on gains or losses relative to a reference point. In this paper we use the PEAK and END variables (the highest and most recent utility derived from investment returns in the period) as the reference value in the asset pricing framework. We test the asset pricing performance of the peak-end rule, and thus of Prospect Theory, using CRSP data. Our data set is the most complete available (daily and monthly) price history of the broad US stock market from 1927 to 2014. Previewing our results, we find

\footnotetext{
${ }^{2}$ See Lo, Mamaysky and Wang (2000) for a summary of these.
} 
evidence of peak-end behaviour by investors, supporting the cognitive model of agent's behaviour proposed by Prospect Theory. Our results suggest that Peak-End behaviour by investors occurs, and that a simple two factor Peak-End model can more comprehensively explain the variations in returns between portfolios sorted by firm size and momentum than popular factor models. We find that this behaviour is not captured by existing factor models, namely; the single-factor CAPM, the Fama-French Three-Factor Model, the Carhart Four-Factor Model, and the Fama-French FiveFactor Model. Moreover, augmenting these models by adding PEAK or END variables, or both, improves their ability to more thoroughly explain differences in portfolio returns.

The paper contributes to the literature in different ways. First, we are the only study that conducts empirical tests of the peak-end rule in explaining stock prices and returns. We confirm the existence of peak-end behaviour by investors in pricing assets, based on an extensive analysis of US stock market returns. Second, we extend prior research on associations of Prospect Theory with finance. Previous studies on pricing implications of Prospect Theory focus upon the convex portion of the value function (Barberis and Xiong, 2009), or the probability weighting function aspect (Barberis and Huang, 2008). In our research, we pay our attention on another aspect of Prospect Theory, namely, reference dependence. Furthermore, we propose a new empirical pricing model to explain the expected return of stocks. Our proposed model incorporates the insights of both expected utility theory and prospect theory. We augment the single factor CAPM by adding the PEAK and END variables to systematic risk. We find overwhelming evidence that the CAPM model is significantly improved, if the PEAK and END are included as explanatory variables. Our new seven factor CAPM which incorporates the peak and the end as additional explanatory variables is in our opinion the most accurate asset pricing model in the financial world, and should 
be used by both academics and practitioners to conduct research and investment strategies based on financial returns.

The remainder of the paper is organised as follows; Section 2 first discusses the literature on empirical performance of the CAPM and its extensions. We then review the cognitive models developed to explain the observed deficiencies of these. Section 3 describes the data we used, and outlines our analytical framework. Section 4 analyses our empirical results. Section 5 summar ises our findings, presents our conclusions and suggestions for further work.

\section{Literature review}

Since the introduction of the CAPM (Sharpe, 1964; Lintner, 1965) scholars have been investigating its empirical properties. The most important prediction of the model is that the expected return of an asset is equal to the beta of the asset multiplied by the expected excess return on the market portfolio ${ }^{3}$. Anomalies of expected returns not explained by the CAPM were soon identified. Moreover, Roll (1977) shows that the model was not testable, since it involves a joint hypothesis involving the CAPM and market efficiency. Nevertheless, empirical research continues because of the model's usefulness to investors and firms. The limitations of the CAPM in consistently explaining the cross-section of asset returns led to the emergence of a diversity of alternative empirical asset pricing models. Tests of the ex-post empirical CAPM suggest that it is linear in beta, with a positive slope, over long time periods. However, they also suggest that the single risk factor, beta, does not fully explain security returns. ${ }^{4}$ The addition of extra factors helps in explaining the fraction of security returns not explained by beta. Additional factors found to

\footnotetext{
${ }^{3}$ The asset's beta is equal to the covariance of the asset's returns with the returns on the market portfolio, divided by the variance of the market portfolio returns.

${ }^{4}$ See among others, Black, Jensen, and Scholes (1972), Miller and Scholes (1972), Fama and Macbeth (1973) and Shanken (1985b).
} 
have explanatory power include; Price/earnings ratios (Basu, 1977). Dividend yields (Litzenburger and Ramaswamy, 1979). Firm size (Banz, 1981; Reinganum, 1981b). More recently, Fama and French (1993) add both firm size, and value risk factors, in their three-factor version of the CAPM. The Carhart (1997) four-factor model additionally includes a momentum risk factor, and the FamaFrench (2015) five-factor model also includes profitability and investment factors. Ross (1976) proposes the Arbitrage Pricing Theory (APT) a more general alternative to the CAPM in which security returns are a linear combination of multiple factors. The APT encompasses the CAPM as a special case. Empirical tests of the APT by Roll and Ross (1980) suggest asset returns are explained by three or possibly four factors, and that the volatility of the asset's own returns is not one of these. In comparative tests of the CAPM and APT, Chen (1983) found the APT explains a statistically significant percentage of CAPM residual variance, but not vice versa. Chen also discovers last period returns were not an explanatory factor, and that that firm size added no explanatory power. This latter finding contrasts with Reinganum (1981a) who rejects the APT because returns vary with firm size. Chen, Roll, and Ross (1986) identify four macroeconomic variables they consider to be significant in explaining asset returns in the APT. However, it is not possible mathematically to definitively identify the drivers of security returns by factor analysis.

More recently, Hodrick and Zhang (2001) evaluate the specification errors in eight asset pricing models proposed as improvements to the CAPM. They compare all the models using a common data set. Namely, the 25 size and book-to-market portfolios constructed as in Fama and French (1993). Their comparison is based on the methodology of Hansen and Jagannathan (1997). The models are all tested in linearized form. They are a single factor reference model, the CAPM, the Breeden (1979) consumption CAPM (CCAPM), the Jagannnathan and Wang (1996) conditional CAPM, the Campbell (1996) intertemporal asset pricing model, the Cochrane (1996) production 
based asset pricing model. The aforementioned models are all based on economic theories. The following empirical models were also tested; the Fama-French (1993) three-factor model, and also the Fama-French (1993) five-factor model, additionally includes two bond market risk factors ${ }^{5}$. Their results suggest that the Campbell (1996) model is capable of correct pricing, but is unstable in the parameters. All of the models fail to correctly price returns in the robustness tests applied. Among their ideas for further research the authors suggest that transaction costs, short sales constraints, liquidity, and the market impact of trading individual assets may be important influences on asset pricing model performance.

Florackis, Gregoriou, and Kostakis (2011) investigate these issues using daily data for all stocks listed on the London stock exchange over the period 1991-2008. Their findings support the view that it is the compound effect of trading frequency and transaction costs, rather than each in isolation, that matters for asset pricing. In this study the authors construct a set of value-weighted and equal-weighted decile portfolios of stocks sorted by the Return to Volume (RtoV) price impact ratio (Amihud, 2002 ratio). They then compute a second set of portfolios, but this time sorted by their proposed alternative Return to Turnover (RtoTR) price impact ratio. This modifies Amihud's ratio by replacing the securities trading volume with its turnover ratio in the denominator. The effect of this is to reduce the size bias present in the Amihud ratio which limits the ability to separate size effects from liquidity effects. They perform asset pricing tests by estimating the abnormal performance of the portfolios using the CAPM, the Fama-French (1993) three-factor model, and the Carhart (1997) four-factor model, which also incorporates a momentum risk factor. The results of the asset pricing tests revealed that the CAPM was unable to fully account for the abnormal returns in the portfolios sorted by RtoV, unlike the Fama-French (1993) model and the

\footnotetext{
5 These are a maturity risk factor, and a default risk factor.
} 
Carhart (1997) model. None of these three commonly used specifications could account for the abnormal returns of the portfolios sorted by RtoTR. These results suggest that trading frequency and transaction costs cannot be neglected in asset pricing models. Fama and French (2015) describe and test a five-factor model which adds profitability and investment risk factors to the Fama-French (1993) three-factor model. They find that the addition of the two extra factors renders the value factor redundant in explaining average returns. Moreover, the five factor model exhibits a size bias and does not adequately explain returns on small stocks.

The models discussed in the above literature are all based on the expected utility framework. The theoretical basis for this was developed by Von Neumann and Morgenstern (1944), who showed that preferences satisfying certain axioms can be represented as expectations of a utility function. However, experimental studies have since confirmed that agents routinely violate the axioms of expected utility theory when making decisions under risk. In response to these findings, researchers developed theoretical models attempting to better explain agents observed decisionmaking behaviour, without invoking expected utility theory. Such theories include; Weightedutility theory (Chew and MacCrimmon, 1979; Chew, 1983) implicit EU (Chew, 1989; Dekel, 1986), disappointment aversion Gul(1991), regret theory (Bell, 1982; Loomes and Sugden, 1982), rank-dependent utility theory (Quiggin, 1982; Segal, 1987,1989; Yaari, 1987), and prospect theory (Kahneman and Tversky, 1979; Tversky and Kahneman, 1992). Of these theories the latter, prospect theory, is most consistent with experimental results. Moreover, it has a number of appealing theoretical properties.

The other theories mentioned merely weaken the Von Neumann and Morgenstern axioms of expected utility theory, for the most part. Prospect theory, by contrast, attempts to capture agents decision-making under risk in the most parsimonious fashion. As originally proposed by 
Markowitz (1952), prospect theory defines utility over gains and losses (returns) rather than end of period levels of wealth. This is consistent with the way agents typically evaluate outcomes of risky decisions, as relative to reference (earlier) values, rather than in absolute terms. Kahneman et al (1993) conjecture that the decision-making process involved, is one whereby agent's expectations are "anchored" to the most recent and best (worst) outcomes. They call this the peakend rule. The peak-end rule has been empirically validated in a number of experimental settings, and is supported by the psychological literature ${ }^{6}$. In an asset pricing framework, a natural interpretation is that the reference values involved represent the highest in-period return, and the most recent end of period return. (e.g. the highest and most recent utility derived from investment returns in the period).

Several authors have applied elements of prospect theory to the study of security returns and asset pricing7. The studies involved are almost exclusively theoretical, and or use simulated data. Excepting Shumway (1998), who investigates loss aversion, empirical studies are practically nonexistent. We attempt to fill this gap in the literature by empirically validating prospect theory, and more specifically, the peak end-rule, in the field of financial asset pricing.

\section{Data, and Analytical Framework}

Following Fama and French (2015), we test all our specifications on a common data set. Like the former, we use 25 portfolios constructed as in Fama and French (1993). Specifically; We use the U.S. Research Returns Data 25 value-weighted portfolios (daily and monthly) sorted by size and

\footnotetext{
${ }^{6}$ See e.g. Fredrickson (2000) and Kahneman (2000) for a review.

7 These include; Epstein and Zin (1990, 1991, 2001), Benartzi and Thaler (1995), Bekaert, Hodrick, and Marshall (1997), Shumway (1998), Ang, Bekaert, and Liu (2005), Barberis and Huang (2001), Gomes (2005), Barberis, Huang, and Santos (2001).
} 
momentum, together with the associated momentum risk factors, and the Fama-French three factor model and five factor model risk factors. We obtain the risk factors from the Kenneth R. French Data Library, together with the applicable one-month T-bill rates. ${ }^{8}$ Our reasons for using this data are several. The database includes a full history of returns for all CRSP firms incorporated in the US and listed on the NYSE, AMEX, or NASDAQ exchanges, for which data is available. Thus, it provides the most complete history of returns possible for the broad US stock market from 1927 to 2014. The data is updated annually to reflect changes in the CRSP database. Given that historical returns can change if CRSP revises its database, the full history of returns is reconstructed each time the portfolios are updated. Use of this data also eases comparability with the results of Fama and French (1993), Carhart (1997), Hodrick and Zhang (2001), Fama and French (2015), and others who have used the same data. The full sample period we use is 1927:01 to 2014:12 giving 1056 monthly observations.

We perform our analys is using the full sample period. We also divide the full sample period into eight sub-samples of 132 months (11 years) and undertake a separate sub-period analysis on each sub-sample. In order to provide reliable econometric estimates, we test thirteen different model specifications on the full sample period and independently on each sub-period. Our test assets (dependent variables) are the excess returns generated by the 25 portfolios. We also add a $26^{\text {th }}$ asset, the excess return of Portfolio 25 - Portfolio 1 (big minus small). We compute the excess returns by subtracting the T-bill rate from each portfolio return. We examine how well each of our

\footnotetext{
${ }^{8}$ For more information readers are referred to the following web resources http://mba.tuck.dartmouth.edu/pages/faculty/ken.french/ftp/25 Portfolios ME Prior 122 CSV.zip http://mba.tuck.dartmouth.edu/pages/faculty/ken.french/ftp/25 Portfolios ME Prior 122 Daily CSV.zip http://mba.tuck.dartmouth.edu/pages/faculty/ken.french/ftp/F-F Momentum Factor CSV.zip http://mba.tuck.dartmouth.edu/pages/faculty/ken.french/ftp/F-F Momentum Factor daily CSV.zip
} 
specifications priced these portfolio excess returns. Additionally, we calculate four further models which include the RMW and CMA profitability and investment risk factor from the Fama and French (2015) five-factor model for the 618 months for which these factor are available, together with four 132 month-sub period analyses using the same sub-periods as for our specifications 1) to 13$)$.

\subsection{Asset Pricing tests}

In order to assess the extent to which peak-end behaviour by investors explains risk-adjusted returns, we first analyse the Specifications 1) -13) in Table 1 on the full data set, and then independently on each of the 8 sub-periods;

\section{[INSERT TABLE 1 HERE]}

Specification 1) assesses the power of the peak-end hypothesis in isolation to explain excess portfolio returns. In Specification 1) $r_{i t}-r_{f t}$ is the portfolio $i$ alpha. $M a x P i_{t-1}$ is the monthly excess return for portfolio $i$ implied by the highest daily return occurring in the previous month. This is the PEAK variable. $\mathrm{Pi}_{t-1}$ is the monthly excess return for portfolio $i$ for the previous month, this is the END variable. $\varepsilon_{i t}$ is a zero-mean residual. Specification 2) is the single factor CAPM. The variable $M K T_{t}$ in Specification 2$)$ is $\left(r_{M K T t}-r_{f t}\right)$, and represents the excess return on the market at time $t$. Specifications 3), 4), and 5) respectively, add first the peak factor $\operatorname{MaxPi}_{t-1}$, then the end factor $P i_{t-1}$, and finally both together to the single CAPM risk factor. Specification 6) is the Fama and French (1993) three-factor model, which adds firm size and value factors to the single CAPM

factor. Specifications 7), 8), and 9) respectively add first the peak factor $M a x i_{t-1}$, then the end 
factor $\mathrm{Pi}_{t-1}$, and finally both together to the three Fama and French (1993) risk factors. Specification 10) is the Carhart (1997) model which extends the Fama and French (1993) threefactor model by additionally including a momentum factor. As before specifications 11), 12), and

13) respectively add first the peak factor $M a x P i_{t-1}$, then the end factor $P i_{t-1}$, and finally both together to the four Carhart (1997) factors.

Fama and French (2015) extended their Fama and French (1993) three factor model, arguing that it does not explain the variation in average returns related to profitability and investment. Thus, they proposed the five-factor model, Specification 14) in Table 1. This includes two additional factors, $R M W_{t}$ and $C M A_{t}$, intended to capture profitability and investment effects respectively.

If, in any of the specifications in Table 1, the exposure to the risk factors truly explains all variation in expected returns, then the intercept term $\alpha_{i}$ is zero for all securities and portfolios $i$, in that case.

\section{Empinical Results}

Table 2 reports the alphas of the 25 value-weighted portfolios formed on size and momentum Column A includes full-sample results for specifications 1) to 9) for all months from January 1927 - December 2014. Following Fama and French (2015) we do not report results for specifications 10) to 14) based on the Carhart (1997) model. This is because the addition of a momentum risk factor produces trivial changes as its regression coefficients are close to zero. Moreover, momentum is already accounted for in the formation of the portfolios we use as they are sorted by momentum. 


\section{[INSERT TABLE 2 HERE]}

The single factor CAPM suggests that asset returns should be unaffected by firm size (or momentum). However, we observe that in all cases the alphas for portfolio 25 (the largest firms) differ from those for portfolio 1 (the smallest firms). The P25-P1 alpha coefficients for our specification 1), a simple two factor peak-end model, is -0.15 and the difference is highly significant with a t-statistic of 18.29. Our specification 2) is the single factor CAPM. The P25-P1 alpha for our specification 2) is -1.37 and the t-statistic is much smaller at 5.46 . However, the difference is still significant at the $1 \%$ level. We observe that the coefficient differences for both of these specifications are negative. However, the alpha for specification 1) is 1.22 greater than for specification 2), the CAPM.

In specification 3) we add the PEAK variable to the CAPM. The P25-P1 alpha coefficient difference for specification 3 increases by 1.85 over the CAPM to becomes positive at 0.48 with a t-statistic of 5.34. Specification 4) adds the END variable to the CAPM. This results in a negative coefficient difference of -1.05 with t-statistic of 5.38 . However, this difference is 0.32 larger than the -1.37 of the single factor CAPM. Specification 5) adds both the PEAK and END variables to the CAPM. In this case the difference is 0.39 with t-statistic of 5.32 . This is 1.76 greater than for the CAPM alone.

Specification 6) is the Fama-French three factor model. This yields a negative P25-P1 alpha coefficient difference of -1.04 with t-statistic of 4.87 , a slightly larger result than the single factor CAPM, though less than our specification 1). When we add the PEAK variable to 6) in specification 7), the difference becomes a positive 0.26 with t-statistic of 4.83 , an increase in alpha 
of 1.3 over the FF three factor model. This difference though is less than in the case of specification 3). Adding the END variable to the FF three factor model produces a negative alpha coeffic ient difference of -0.91 with $t$-statistic of 4.86 , an increase of 0.13 . This though is greater than in the case of specification 4). Specification 9) adds both the PEAK and END variables to the FF three factor model. In this case the alpha difference is 0.25 with t-statistic of 4.82 , an increased difference of 1.29 in compared to the FF three factor model, and an increase of 1.62 compared to the CAPM. To sum up, all our full-sample P25-P1 results in Column A of Table 2 are significant at the $1 \%$ level. The specification 1) PEAK+END coefficient difference is 1.22 greater than the CAPM.

\subsection{Sub Period Analysis}

Column B includes results for Specifications 1) to 9) for the January 1927 - December 1937. The P25-P1 alpha coefficient difference for specification 1), is 0.01 and is significant at the $1 \%$ level with a t-statistic of 5.70 . The remaining results are all significant at the $5 \%$ level. In contrast to Specification 1), the difference for the single factor CAPM Specification 2), is -4.20 with a tstatistic of 2.45. Adding the PEAK value in Specification 3, increases the difference by 5.20 to 1.01, with a t-statistic of 2.41. Specification 4 adds the END value, increasing the difference by 0.97 to -3.22 , with t-statistic of 2.41. Specification 5) adds both the PEAK and END values, increasing the single factor CAPM alpha coefficient difference by 4.99 to 2.39 .

Specification 6 is the FF three factor model. Its P25-PI alpha coefficient difference is -3.62 with tstatistic of 2.19. Adding the PEAK value in Specification 7) increases this difference by 2.84 to 0.78 with t-statistic of 2.18. Specification 8) includes the END factor, increasing the Specification 6) difference by 0.27 to -3.35 with t-statistic of 2.19 . Specification 9) includes both the PEAK and 
END factors, increasing the FF three factor alpha coefficient difference by 2.94 to -0.68 with tstatistic of 2.18 .

Column C, covering the period Jan 1938 to Dec. 1948, all of the P25-P1 results are highly significant at the $1 \%$ level. The Specification 1) alpha coefficient difference is -2.74 with t-statistic of 20.04, compared to the specification 2) difference of -3.15 with t-statistic of 3.84 . Adding the PEAK, END, and both factors to Specifications 1) and 6) produces a similar pattern of increases in the alpha coefficient differences as seen in Columns A and B.

Column D, covers the period Jan 1949 to Dec. 1959. The P25-P1 results for Specifications 1) to 6) are all significant at the $1 \%$ level. The remaining results are significant at the $5 \%$ level. The alpha coefficient difference for Specification 1) is -1.35 , again with a very large t-statistic of 21.13. Again, adding the PEAK, END, and PEAK+END to the single factor CAPM increases the difference, but by smaller amounts than seen in the previous columns. In contrast to the results seen for the previous sub-periods, adding the PEAK value and PEAK+END values to Specification 6), the FF three factor model, in Specifications 7) and 9) decreases the alpha coefficient difference. This effect is clearly due to the PEAK value as adding the END alone in specification 8) increases the alpha coefficient difference by 0.03 from -0.98 to -0.73 . The $t$-statistic here is the same for Specifications 6) to 9) at 2.25 .

Column E covers the period Jan. 1960 to Dec. 1970. Here, the P25-P1 alpha coefficient difference for specification 1) is -1.79 with a large t-statistic of 10.96 , significant at the $1 \%$ level. The remaining results are all significant at the $5 \%$ level. Adding the PEAK value to Specification 2) and Specification 6) in Specifications 3) and 7) respectively, decreases the difference by -0.20 from -1.34 to -1.54 in the first case, and by -0.10 from -0.85 to -0.95 in the latter case. However, 
adding the END value and PEAK+END values to Specifications 2) and 6) results in small increases in the alpha coefficient differences.

Column F reports the results for the period Jan 1971 to Dec. 1981. The P25-P1 results for this period repeat the pattern seen in Columns A and B. The alpha coefficient difference for Specification 1) is 0.89 with a large t-statistic of 8.18 significant at the $1 \%$ level. The remaining results are all significant at the 5\% level. Here, adding the PEAK value to Specifications 2) and 6) in Specifications 3) and 7) results in an increased difference. Adding the END value in Specifications 4) and 7) produces a smaller increase, while adding both the PEAK and END in Specifications 5) and 9) produces increases comparable to adding the PEAK value alone.

Column G covers the period Jan. 1982 to Dec. 1992. None of the P25-P1 results for this period are statistically significant at even the $10 \%$ level. However, the same pattern of increase in the alpha coefficient differences is observed when Specifications 2) and 6) are augmented by adding the PEAK, END, and both variables. This time period encompasses the stock market crash of 1987, and the global downturn of the early 1990's.

Column H covers the period Jan. 1993 to Dec. 2003. The P25-P1 result for Specification 1) for this period is statistically significant at the $1 \%$ level with alpha coefficient difference of 1.44 and t-statistic of 5.96. All other results are statistically insignificant. However, the pattern of increase in differences previously seen when Specifications 2) and 6) are augmented is repeated here. This time period encompasses the Asian Financial Crisis, the Russian debt default, the collapse of Long Term Capital Management, and the Dot-Com stock market collapse.

Finally, Column I covers Jan. 2004 to Dec. 2014. Here the P25-P1 result for Specification 1) is again statistically significant at the $1 \%$ level with alpha coefficient difference of 0.44 and t-statistic 
of 3.13. None of the remaining results are statistically significant at normal levels. However, the familiar pattern of increase in differences when Specifications 2) and 6) are augmented is repeated, albeit with smaller increments. This time period encompasses the financial crisis of 2007-2008 and its aftermath.

The significance of our results can be more clearly seen in Table 3 . This tabulates the absolute value of the Portfolio 25 - Portfolio 1 constant coefficient differences. The smaller the difference, the more fully a specification explains variations in expected returns, the intercept term $\alpha_{i}$ being zero for all portfolios in the case of a complete explanation.

\section{[INSERT TABLE 3 HERE]}

In table 3 Column A we see that for the full sample period, the simple Peak-End behavioural model has the smallest coefficient difference of all, and thus explains the variance in portfolio returns more fully than the single factor CAPM (Specification 2) or the Fama-French three factor model. Moreover, when the PEAK and END variables together are added to these models, the constant coefficient is sharply reduced. For all of the sub periods excepting $G$ and I adding the PEAK, END, or both to the single factor CAPM and the Fama-French three factor model reduces their alphas. This strongly suggests Peak-End behaviour by investors occurs, but is not captured in these models.

\subsection{Fama-French (2015) Five Factor Model}

\section{[INSERT TABLE 4 HERE]}

Table 4 presents the difference in coefficients between portfolios P25 and P1 related to the FF 5 factor model, and its extensions augmented by the PEAK value, the END value, and both. Column 
A* shows results for the full sample period of Jul.1963 - Dec.2014. Excepting Specification 1) which is significant at the $1 \%$ level with a t-statistic of -14.07 , these are all significant at the $5 \%$ level with virtually identical t-statistics. Adding the PEAK value to the FF 5 factor specification reduces the difference in coefficients from 0.49 by -0.52 to -0.03 . Adding the END value increases the difference by 0.01 , while adding both PEAK and END reduces the difference by -0.47 . Results for sub-period F covering the time period Jan. 1971 to Dec. 1981 are again all significant at the $5 \%$ level with nearly identical t-statistics, excepting Specification 1) with t-statistic of 8.18 which is at the $1 \%$ level. Augmenting the FF 5 factor specification with the PEAK, END, and both, leads to a decrease in the coefficient difference in all cases. Results for the remaining three sub periods, G, H, and I, are statistically significant only for Specification 1) which is significant at the $1 \%$ level. However, augmenting the FF 5 factor specification with the END reduces the coefficient difference for period G. For period H, the coefficient difference is reduced by adding the PEAK value, while for I, it is also reduced by adding the END. The significance of these results is more clearly evident in Table $5 .^{9}$

\section{[INSERT TABLE 5 HERE]}

Table 5 Column A* reports results for the full sample period for which the Fama-French five factor risk factors are available. Namely; July 1963 to December 2014. The Specification 1) coeffic ient difference at 0.59 is slightly higher than Specification 14), the Fama-French five-factor model, at 0.49. However, adding the PEAK and END variables to the latter substantially reduces the constant coefficient to 0.02 . This suggests that Peak-End behaviour by investors is not captured by the additional profitability and investment risk factors included in this model. In the sub period

\footnotetext{
${ }^{9}$ Note even though we show significant abnormal performance of our model compared to the previous literature, the alphas obtained are not directly comparable because we compute a dynamic rather than a static econometric model.
} 
analysis covering periods $\mathrm{F}$ to I the constant coefficient is reduced by adding either the PEAK or END to the model, except for period I. ${ }^{10}$

\section{Summary and Conclusions}

This study is the first empirical test of Prospect Theory, specifically, the Peak-End rule, in explaining stock prices and returns. Our dataset represents a full history of returns for all CRSP firms incorporated in the US and listed on the NYSE, AMEX, or NASDAQ exchanges, over the time period of 1927-2014. The data consists of the U.S. Research Returns Data, 25 value-weighted portfolios (daily and monthly) sorted by size and momentum, together with the associated FamaFrench three factor model, and five factor model risk factors, following Fama and French (1993), Carhart (1997), Hodrick and Zhang (2001), Fama and French (2015), and others who have used the same data. The full sample period we used is 1927:01 to 2014:12 giving 1056 monthly observations.

The joint hypothesis of (weak-form) market efficiency and the (single-factor) CAPM suggest the abnormal returns of an asset over and above the market risk premium can be entirely explained by a single risk factor, the coefficient "beta". Moreover, it suggests that asset returns should be unaffected by other factors such as firm size (market capitalisation), or momentum. It is well known however, that returns are not fully explained by the single-factor CAPM. Hence, the development of extensions such as the Fama-French (1993) three factor model, Carhart (1997) four factor model, and more recently the Fama French (2015) five factor model.

\footnotetext{
${ }^{10}$ Further robustness was undertaken by examining if the cross sectional variation in our portfolios can be explained by exposure to the peak and end values both in isolation and jointly, using the methodology in Fama and MacBeth (1973). The results are quantitatively similar to the time series analysis reported in the paper. The cross sectional findings are not reported in order to save space but are available from the authors upon request.
} 
Our results suggest that an alternative approach, the simple two-factor Peak-End behavioural model, can more thoroughly explain the differences in returns observed to occur between portfolios of large-capitalisation, large-momentum stocks and small-capitalisation small-momentum stocks. For our full sample, the two-factor Peak-End model has an alpha (constant) coefficient of only 0.15, smaller than either, the single-factor CAPM, or the Fama-French Three-Factor model. Augmenting both of these models with the PEAK and END variables reduces their alphas, but still they remain substantially larger than the two-factor Peak-End model. However, the Peak-End model exhibits a larger alpha of 0.59 for the smaller data set available for testing the Fama-French Five-Factor model (July 1963 to December 2014). Even so, augmenting the Five-Factor model with the PEAK and END variables, reduces its' alpha from 0.49 to 0.02 . These findings support the existence of Peak-End behaviour by investors. Moreover, they suggest that this peak-end effect is not captured by the aforementioned models. Neither is the effect impounded in the additional profitability and investment risk factors included in the Fama-French Five-Factor model. However, the reduced alpha of 0.02 observed for our augmented Specification 14), a seven-factor extension of this model, suggests the peak-end effect may explain its' size bias.

Our new seven factor CAPM which incorporates the peak and the end as additional explanatory variables is in our opinion the most accurate asset pricing model in the financial world, and should be used by both academics and practitioners to conduct research and investment strategies based on financial returns.

Our results suggest current prices are affected by previous price movements, and that successive prices are not independent, thus adding to the counter evidence for the EMH and Random Walk Hypothesis. 
An obvious extension of this study is to examine higher frequency data, as well as data for other markets and asset classes, for evidence of Peak-end effects. More detailed analysis of results of technical trading strategies, for evidence of Peak-end or other constructs from Prospect Theory may also prove fruitful. 


\section{References}

Amihud, Y. (2002). Illiquidity and Stock Returns: Cross-section and Time-series Effects. Journal of Financial Markets, 5, 31-56.

Ang, A., Bekaert, G., \& Liu, J. (2005). Why stocks may disappoint. Journal of Financial Economics, 76, 471-508.

Aronson, D. (2006). Evidence-Based Technical Analysis: Applying the Scientific Method and Statistical Inference to Trading Signals. New Jersey: John Wiley and Sons. ISBN 978-0-47000874-4.

Banz, R. (1981). The Relationship between Return and Market Value of Common Stocks. Journal of Financial Economics, 9, 3-18.

Barberis, N., \& Huang, M. (2001). Mental accounting, loss aversion, and individual stock returns. Journal of Finance, 56, 1247-1292.

Barberis, N., \& Huang, M. (2008). Stocks as Lotteries: The Implications of Probability Weighting for Security Prices. American Economic Review, 98, 2066-2100.

Barberis, N., \& Xiong, W. (2009). What Drives the Disposition Effect? An Analysis of a LongStanding Preference-Based Explanation. Journal of Finance, 64, 751-784.

Barberis, N., Huang, M., \& Santos, J. (2001). Prospect theory and asset prices. Quarterly Journal of Economics, 116, 1-53.

Basu, S. (1977). Investment Performance of Common Stocks in Relation to Their Price-Earnings Ratios: A Test of the Efficient Market Hypothesis. Journal of Finance, 32, 663-682.

Bekaert, G., Hodrick, R., \& Marshall, D. (1997). The implications of first-order risk aversion for asset market risk premiums. Journal of Monetary Economics, 40, 3-39.

Bell, D. (1982). Regret in decision making under uncertainty. Operations Research, 30, 961-981. 
Benartzi, S., \& Thaler, R. (1995). Myopic loss aversion and the equity premium puzzle. Quarterly Journal of Economics, 110, 75-92.

Black, F. (1972). Capital Market Equilibrium with Restricted Borrowing. Journal of Business, 45, 444-454.

Black, F., Michael C. Jensen, \& Scholes, M. (1972). The capital asset pricing model: Some empirical tests. In Michael C. Jensen. (Ed.): Studies in the Theory of Capital Markets (Praeger, New York).

Breeden, D. (1979). An intertemporal asset pricing model with stochastic consumption and investment opportunities. Journal of financial Economics, 7, 265-296.

Campbell, J. (1996) Understanding risk and return. Journal of Political Economy, 104, $298-345$.

Carhart, M. (1997). On persistence in mutual fund performance. Journal of Finance, 52, 57-82.

Chen, N. (1983). Some Empirical Tests of the Theory of Arbitrage Pricing. The Journal of Finance, 38, 1393-1414.

Chen, N., Roll, R., \& Ross, S.A. (1986). Economic forces and the stock market. Journal of business, 59, 383-403.

Chew, S. (1983). A generalization of the quasilinear mean with applications to the measurement of income inequality and decision theory resolving the allais paradox. Econometrica, 51, $1065-1092$.

Chew, S. (1989). Axiomatic utility theories with the betweenness property. Annals of Operations Research, 19, 273-98.

Chew, S., \& MacCrimmon, K. (1979). Alpha-nu choice theory: An axiomatization of expected utility. Working Paper (Univers ity of British Columbia, Vancouver, BC). 
Cochrane, J. (1996). A cross-sectional test of an investment-based asset pricing model. Journal of Political Economy, 104, 572-621.

Dekel, E. (1986). An axiomatic characterization of preferences under uncertainty: weakening the independence axiom. Journal of Economic Theory, 40, 304-18.

Epstein, L., \& Zin, S. (1990). First-order'risk aversion and the equity premium puzzle. Journal of monetary Economics, 26, 387-407.

Epstein, L., \& Zin, S. (1991). Substitution, risk aversion, and the temporal behavior of consumption growth and asset returns II: An empirical analysis. Journal of Political Economy, 99, 263-286.

Epstein, L., \& Zin, S. (2001). The independence axiom and asset returns. Journal of Empirical Finance, 8, 537-572.

Fama, E., \& French, K. (1993). Common risk factors in the returns on stocks and bonds. Journal of Financial Economics, 33, 3-56.

Fama, E., \& French, K. (2015). A Five-factor Asset Pricing Model. Journal of Financial Economics, 116, 1-22.

Fama, E., \& MacBeth, J. (1973). Risk, return, and equilibrium: Empirical tests. The journal of political economy, 81, 607-636.

Florackis, C., Gregoriou, A., \& Kostakis, A. (2011). Trading frequency and asset pricing on the London Stock Exchange: Evidence from a new price impact ratio. Journal of Banking \& Finance, 35, 3335-3350.

Fredrickson, B. (2000). Extracting meaning from past affective experiences: The importance of peaks, ends, and specific emotions. Cognition \& Emotion, 14, 577-606. 
Fredrickson, B., \& Kahneman, D. (1993). Duration neglect in retrospective evaluations of affective episodes. Journal of Personality \& Social Psychology, 65, 44-55

Gomes, F. (2005). Portfolio Choice and Trading Volume with Loss-Averse Investors. The Journal of Business, 78, 675-706.

Gul, F. (1991). A theory of disappointment in decision making under uncertainty, Econometrica, 59, 667-686.

Hansen, L., \& Jagannathan, R. (1997). Assessing specification errors in stochastic discount factor models. Journal of Finance, 52, 557-590.

Hodrick, R., \& Zhang, X. (2001). Evaluating the specification errors of asset pricing models. Journal of Financial Economics, 62, 327-376.

Jagannathan, R., \& Wang, Z. (1996). The conditional CAPM and the cross-section of expected returns. The Journal of finance, 51, 3-53.

Kahneman, D. (2000). Evaluation by moments: Past and future. In Kahneman D., and Tversky, A. (Eds.): Choices, values, and frames. New York: Cambridge University Press and Russel Sage Foundation, 693-708.

Kahneman, D., \& Tversky, A. (1979). Prospect Theory: An Analysis of Decision Under Risk. Econometrica, 47, 263-291.

Kahneman, D., Fredrickson, D., Schreiber, C., \& Redelemeier, D. (1993). When more pain is preferred to less: Adding a better end. Psychological Science, 4, 401-405.

Lintner, J. (1965). Security Prices, Risk, and Maximal Gains from Diversification. Journal of Finance, 20, 587-615. 
Lintner, J. (1969). The Aggregation of Investor's Diverse Judgments and Preferences in Purely Competitive Security Markets. The Journal of Financial and Quantitative Analysis, 4, 347400.

Litzenberger, R., \& Ramaswamy, K. (1979). The effect of personal taxes and dividends on capital asset prices: Theory and empirical evidence. Journal of Financial Economics, 7, 163-195.

Lo, Andrew W., Mamaysky, H. \& Wang, J. (2000). Foundations of Technical Analys is: Computational Algorithms, Statistical Inference, and Empirical Implementation. Journal of Finance, 55, 1705-1765.

Loomes, G., \& Sugden, R. (1982). Regret theory: an alternative theory of rational choice under uncertainty. The Economic Journal, 92, 805-824.

Markowitz, H. (1952). Portfolio Selection. Journal of Finance, 7, 77-91.

Merton, R. (1973). An Intertemporal Capital Asset Pricing Model. Econometrica, 41, 867-888.

Miller, M., \& Scholes, M. (1972). Rates of return in relation to risk: A re-examination of some recent findings. In Michael C. Jensen (Ed.): Studies in the Theory of Capital Markets (Praeger, New York).

Mossin, J. (1966). Equilibrium in a Capital Asset Market. Econometrica, 34, 768-783.

Quiggin, J. (1982). A theory of anticipated utility. Journal of Economic Behavior and Organization, 3, 323-343.

Reinganum, M. (1981a). The Arbitrage Pricing Theory: Some Empirical Results. Journal of Finance, 36, 313-321.

Reinganum, M. (1981b). Misspecification of Capital Asset Pricing: Empirical Anomalies Based on Earnings Yields and Market Values. Journal of Financial Economics, 9, 19-46. 
Roll, R. (1977). Critique of the Asset Pricing Theory's Tests. Journal of Financial Economics, 4, 129-176.

Roll, R., \& Ross, S. (1980). An Empirical Investigation of the Arbitrage Pricing Theory. Journal of Finance, 35, 1073-1103.

Ross, S. (1976). The Arbitrage Theory of Capital Asset Pricing. Journal of Economic Theory, 13, 341-360.

Segal, U. (1987). Some remarks on Quiggin's anticipated utility. Journal of Economic Behavior and Organization, 8, 145-154.

Segal, U. (1989). Anticipated utility: a measure representation approach. Annals of Operations Research, 19, 359-373.

Shanken, J. (1985). Multivariate tests of the zero-beta CAPM. Journal of financial economics, 14, 327-348.

Sharpe, W. (1963). A Simplified Model for Portfolio Analysis. Management Science, 9, 277-293.

Sharpe, W. (1964). Capital Asset Prices: A Theory of Market Equilibrium under Conditions of Risk. Journal of Finance, 19, 425-442.

Shumway, T. (1998). Explaining returns with loss aversion. Mimeo. University of Michigan Business School. Available at https://ssrn. com/abstract=58442.

Subrahmanyam, A. (2008). Behavioural Finance: A Review and Synthesis. European Financial Management, 14, 12-29.

Thaler, Richard H. (Ed.). (2005). Advances in Behavioral Finance, Volume II. Princeton University Press.

Treynor, J. (1961). Toward a Theory of the Market Value of Risky Assets. Unpublished manuscript. 
Tversky, A., \& Kahneman, D. (1992). Advances in prospect theory: Cumulative representation of uncertainty. Journal of Risk and Uncertainty, 5, 297-323.

Tversky, A., \& Kahneman, D. (1992). Advances in Prospect Theory: Cumulative Representation of Uncertainty. Journal of Risk and Uncertainty, 5, 297-323.

Von Neumann, J., \& Morgenstern, O. (1944). Theory of games and economic behavior (Vol. 60). Princeton: Princeton University Press.

Yaari, M. (1987). The dual theory of choice under risk. Econometrica, 55, 95-115. 


\section{Table 1: Specifications Tested}

$$
\begin{aligned}
& r_{i t}-r_{f t}=\alpha_{i}+\beta_{i, M a x P i_{t-1}} M a x P i_{t-1}+\beta_{i, P i_{t-1}} P i_{t-1}+\varepsilon_{i t} \\
& r_{i t}-r_{f t}=\alpha_{i}+\beta_{i, M K T_{t}} M K T_{t}+\varepsilon_{i t} \\
& r_{i t}-r_{f t}=\alpha_{i}+\beta_{i, M K T_{t}} M K T_{t}+\beta_{i, M a x P i_{t-1}} \operatorname{MaxPi}_{t-1}+\varepsilon_{i t} \\
& r_{i t}-r_{f t}=\alpha_{i}+\beta_{i, M K T_{t}} M K T_{t}+\beta_{i, P i_{t-1}} P i_{t-1}+\varepsilon_{i t} \\
& r_{i t}-r_{f t}=\alpha_{i}+\beta_{i, M K T_{t}} M K T_{t}+\beta_{i, M a x P i_{t-1}} \operatorname{MaxPi}_{t-1}+\beta_{i, P i_{t-1}} P i_{t-1}+\varepsilon_{i t} \\
& r_{i t}-r_{f t}=\alpha_{i}+\beta_{i, M K T_{t}} M K T_{t}+\beta_{i, S M B 3_{t}} S M B 3_{t}+\beta_{i, H M L_{t}} H M L_{t}+\varepsilon_{i t} \\
& r_{i t}-r_{f t}=\alpha_{i}+\beta_{i, M K T_{t}} M K T_{t}+\beta_{i, S M B 3_{t}} S M B 3_{t}+\beta_{i, H M L_{t}} H M L_{t}+\beta_{i, M a x P i_{t-1}} M a x P i_{t-1}+\varepsilon_{i t} \\
& r_{i t}-r_{f t}=\alpha_{i}+\beta_{i, M K T_{t}} M K T_{t}+\beta_{i, S M B 3_{t}} S M B 3_{t}+\beta_{i, H M L_{t}} H M L_{t}+\beta_{i, P i_{t-1}} P i_{t-1}+\varepsilon_{i t} \\
& r_{i t}-r_{f t}=\alpha_{i}+\beta_{i, M K T_{t}} M K T_{t}+\beta_{i, S M B 3_{t}} S M B 3_{t}+\beta_{i, H M L_{t}} H M L_{t}+\beta_{i, M a x P i_{t-1}} M \operatorname{MxPi}_{t-1}+\beta_{i, P i_{t-1}} P i_{t-1}+\varepsilon_{i t} \\
& r_{i t}-r_{f t}=\alpha_{i}+\beta_{i, M K T_{t}} M K T_{t}+\beta_{i, S M B 3_{t}} S M B 3_{t}+\beta_{i, H M L_{t}} H M L_{t}+\beta_{i, M O M_{t}} M O M_{t}+\varepsilon_{i t} \\
& r_{i t}-r_{f t}=\alpha_{i}+\beta_{i, M K T_{t}} M K T_{t}+\beta_{i, S M B 3_{t}} S M B 3_{t}+\beta_{i, H M L_{t}} H M L_{t}+\beta_{i, M O M_{t}} M_{O M}+\beta_{i, M a x P i_{t-1}} \operatorname{MaxPi}_{t-1}+\varepsilon_{i t} \\
& r_{i t}-r_{f t}=\alpha_{i}+\beta_{i, M K T_{t}} M K T_{t}+\beta_{i, S M B 3_{t}} S M B 3_{t}+\beta_{i, H M L_{t}} H M L_{t}+\beta_{i, M O M_{t}} M O M_{t}+\beta_{i, P i_{t-1}} P i_{t-1}+\varepsilon_{i t} \\
& r_{i t}-r_{f t}=\alpha_{i}+\beta_{i, M K T_{t}} M K T_{t}+\beta_{i, S M B 3_{t}} S M B 3_{t}+\beta_{i, H M L_{t}} H M L_{t}+\beta_{i, M O M_{t}} M O M_{t}+\beta_{i, M_{\text {MxPi }}{ }_{t-1}} \operatorname{MaxPi}_{t-1}+\beta_{i, P i_{t-1}} P i_{t-1}+\varepsilon_{i t} \\
& r_{i t}-r_{f t}=\alpha_{i}+\beta_{i, M K T_{t}} M K T_{t}+\beta_{i, S M B 5_{t}} S M B 5_{t}+\beta_{i, H M L_{t}} H M L_{t}+\beta_{i, R M W_{t}} R M W_{t}+\beta_{i, C M A_{t}} C M A_{t}+\varepsilon_{i t} \\
& r_{i t}-r_{f t}=\alpha_{i}+\beta_{i, M K T_{t}} M K T_{t}+\beta_{i, S M B 5_{t}} S M B 5_{t}+\beta_{i, H M L_{t}} H M L_{t}+\beta_{i, R M W_{t}} R M W_{t}+\beta_{i, C M A_{t}} C M A_{t}+\beta_{i, M a x P i_{t-1}} M a x P i_{t-1}+\varepsilon_{i t} \\
& r_{i t}-r_{f t}=\alpha_{i}+\beta_{i, M K T_{t}} M K T_{t}+\beta_{i, S M B 5_{t}} S M B 5_{t}+\beta_{i, H M L_{t}} H M L_{t}+\beta_{i, R M W_{t}} R M W_{t}+\beta_{i, C M A_{t}} C M A_{t}+\beta_{i, P i_{t-1}} P i_{t-1}+\varepsilon_{i t} \\
& r_{i t}-r_{f t}=\alpha_{i}+\beta_{i, M K T_{t}} M K T_{t}+\beta_{i, S M B 5_{t}} S M B 5_{t}+\beta_{i, H M L_{t}} H M L_{t}+\beta_{i, R M W_{t}} R M W_{t}+\beta_{i, C M A_{t}} C M A_{t}+\beta_{i, M a x P i_{t-1}} M a x P i_{t-1}+\beta_{i, P i_{t-1}} P i_{t-1}+\varepsilon_{i t}
\end{aligned}
$$




\section{Table 2: Portfolio 25 - Portfolio 1 Constant Coefficient Differences}

This table shows the difference in coefficients for the constant term between portfolio P25 and portfolio P1, Portfolio 25 contains the largest capitalisation firms with the largest momentum. Portfolio P1 contains the smallest capitilisation firms with the smallest momentum. Results for the full sample period (Jan.1927 Dec.2014), and 8 consecutive 11 year sub-sample periods are shown. Column A reports the full sample period results. The remaining columns rep ort the subperiod results. The corresponding t-statistics are for a two tailed test of the mean difference between the in-sample predicted values for P25 and P1, in each case. CAPM alpha is the annualized alpha estimate derived from the Capital Asset Pricing Model. FF 3 FACTOR MODEL alpha is the annualized alpha estimate derived from the Fama-French three-factor model.

\begin{tabular}{|c|c|c|c|c|c|c|c|c|c|}
\hline \multirow[b]{2}{*}{ Panels A to I: Results for portfolios P25-P1 } & \multicolumn{9}{|l|}{ P25-P1 } \\
\hline & $A$ & $B$ & C & $D$ & $E$ & $F$ & $G$ & $H$ & $I$ \\
\hline \multirow[t]{2}{*}{ 1) PEAK+END alpha } & -0.15 & 0.01 & -2.74 & -1.35 & -1.79 & 0.89 & 3.59 & 1.44 & 0.44 \\
\hline & $18.29 * * *$ & $5.70 * * *$ & $20.04 * * *$ & $21.13^{* * *}$ & $10.96 * * *$ & $8.18 * * *$ & -0.84 & $5.96 * * *$ & $3.13^{* * *}$ \\
\hline \multirow[t]{2}{*}{ 2) SINGLE FACTOR CAPM alpha } & -1.37 & -4.20 & -3.15 & -0.90 & -1.34 & -1.79 & 0.36 & -0.70 & 0.16 \\
\hline & $5.46^{* * *}$ & $2.45^{* *}$ & $3.84 * * *$ & $2.62 * * *$ & $2.58^{* *}$ & $2.53^{* *}$ & -0.31 & 1.40 & 0.45 \\
\hline \multirow[t]{2}{*}{ 3) SINGLE FACTOR CAPM + PEAK alpha } & 0.48 & 1.01 & -1.25 & -0.86 & -1.54 & 0.25 & 3.08 & 2.65 & 0.58 \\
\hline & $5.34 * * *$ & $2.41 * *$ & $3.82 * * *$ & $2.61 * * *$ & $2.58^{* *}$ & $2.50 * *$ & -0.30 & 1.35 & 0.45 \\
\hline \multirow{2}{*}{ 4) SINGLE FACTOR CAPM + END alpha } & -1.05 & -3.22 & -2.95 & -0.72 & -1.10 & -1.62 & 0.52 & -0.57 & 0.17 \\
\hline & $5.38 * * *$ & $2.41 * *$ & $3.83 * * *$ & $2.61 * * *$ & $2.53 * *$ & $2.52 * *$ & -0.30 & 1.39 & 0.45 \\
\hline \multirow[t]{2}{*}{ 5) SINGLE FACTOR CAPM + PEAK + END alpha } & 0.39 & 0.80 & -1.20 & -0.88 & -1.09 & 0.18 & 3.16 & 2.52 & 0.44 \\
\hline & $5.32 * * *$ & $2.39 * *$ & $3.82 * * *$ & $2.61 * * *$ & $2.53^{* *}$ & $2.49 * *$ & -0.29 & 1.35 & 0.45 \\
\hline \multirow[t]{2}{*}{ 6) FF 3 FACTOR MODEL alpha } & -1.04 & -3.62 & -2.57 & -0.76 & -0.85 & -0.88 & 0.24 & -0.37 & 0.15 \\
\hline & $4.87 * * *$ & $2.19 * *$ & $3.44 * * *$ & $2.25^{* *}$ & $2.24^{* *}$ & $2.22^{* *}$ & -0.28 & 1.27 & 0.43 \\
\hline \multirow[t]{2}{*}{ 7) FF 3 FACTOR MODEL + PEAK alpha } & 0.26 & -0.78 & -0.80 & -0.98 & -0.95 & 0.32 & 1.04 & 1.99 & 0.55 \\
\hline & $4.83^{* * *}$ & $2.18 * *$ & $3.43^{* * *}$ & $2.25 * *$ & $2.24 * *$ & $2.22 * *$ & -0.28 & 1.25 & 0.43 \\
\hline \multirow[t]{2}{*}{ 8) FF 3 FACTOR MODEL + END alpha } & -0.91 & -3.35 & -2.43 & -0.73 & -0.81 & -0.88 & 0.31 & -0.36 & 0.16 \\
\hline & $4.86^{* * *}$ & $2.19 * *$ & $3.44 * * *$ & $2.25 * *$ & $2.24 * *$ & $2.22 * *$ & -0.28 & 1.26 & 0.43 \\
\hline \multirow[t]{2}{*}{ 9) FF 3 FACTOR MODEL + PEAK + END alpha } & 0.25 & -0.68 & -0.73 & -0.98 & -0.76 & 0.39 & 1.33 & 1.92 & 0.41 \\
\hline & $4.82 * * *$ & $2.18 * *$ & $3.43^{* * *}$ & $2.25 * *$ & $2.24 * *$ & $2.22 * *$ & -0.28 & 1.25 & 0.43 \\
\hline
\end{tabular}

\footnotetext{
* The corresponding alpha coefficient is statistically significant at the $10 \%$ level

** The corresponding alpha coefficient is statistically significant at the $5 \%$ level

***The corresponding alpha coefficient is statistically significant at the $1 \%$ level
} 
Table 3: Absolute Values of Portfolio 25 - Portfolio 1 Coefficient Differences

This table shows the absolute values of the differences in coefficients between P25 and P1. Any model that truly explains all variation in expected returns, will have an intercept term of zero for all portfolios. The models with the greatest explanatory power are those with the smallest absolute value for the difference in P25-P1 coefficients.

Panels A to I: Results for portfolios P25-P1

1) PEAK+END alpha

2) SINGLE FACTOR CAPM alpha

3) SINGLE FACTOR CAPM + PEAK alpha

P25-P1

4) SINGLE FACTOR CAPM + END alpha

\begin{tabular}{ccccccccc}
\hline$A$ & $B$ & $C$ & $D$ & $E$ & $F$ & $G$ & $H$ & $I$ \\
\hline 0.15 & 0.01 & 2.74 & 1.35 & 1.79 & 0.89 & 3.59 & 1.44 & 0.44
\end{tabular}

5) SINGLE FACTOR CAPM + PEAK + END alpha

$1.37 \quad 4.20 \quad 3.15$

$0.90 \quad 1.34 \quad 1.79$

0.36

0.70

0.16

$\begin{array}{lll}0.48 & 1.01 & 1.25\end{array}$

$\begin{array}{lll}0.86 & 2.54 & 0.25\end{array}$

3.08

2.65

0.58

$\begin{array}{lll}1.05 & 3.22 \quad 2.95\end{array}$

$0.72 \quad 1.10$

1.62

$0.52 \quad 0.57$

0.17

0.39

$0.80 \quad 1.20$

$0.88 \quad 1.09$

$0.18 \quad 3.16$

2.52

0.44

MINIMUM

0.15

$0.01 \quad 1.20$

$0.72 \quad 1.09$

$0.18 \quad 0.36$

0.57

0.16

6) FF 3 FACTOR MODEL alpha

$1.04 \quad 3.62 \quad 2.57$

$0.76 \quad 0.85$

$0.88 \quad 0.24$

0.37

0.15

7) FF 3 FACTOR MODEL + PEAK alpha

$\begin{array}{llllll}0.26 & 0.78 & 0.80 & 0.98 & 0.95 & 0.32\end{array}$

1.04

1.99

0.55

8) FF 3 FACTOR MODEL + END alpha

$\begin{array}{llllll}0.91 & 3.35 & 2.43 & 0.73 & 0.81 & 0.88\end{array}$

0.31

0.36

0.16

9) FF 3 FACTOR MODEL + PEAK + END alpha

0.25

$0.68 \quad 0.73$

$0.98 \quad 0.76$

0.39

1.33

0.24

0.24

$1.92-0.41$
-3.36

MINIMUM

\section{Table 4: Peak-End and the Fama-French 5 Factor Model}

This table reports the difference in coefficients between P25 containing large capitalisation stocks with large momentum and P1 containing small capitalisation stocks with small momentum. Column A* shows results for the complete sample period (Jul.1963 Dec.2014), for which the Fama-French 5 factor model risk factors are available. The remaining columns contain results for 11 year sub-samples. The corresponding t-statistics for a two tailed test of the mean difference between the in-sample predicted values for P25 and P1, are shown in each case.

Panels A to I: Results for portfolios P25-P1

1) PEAK+END alpha

14) FF 5 FACTOR MODEL

15) FF 5 FACTOR MODEL + PEAK

P25-P1

16) FF 5 FACTOR MODEL + END

17) FF 5 FACTOR MODEL + PEAK + END

\begin{tabular}{ccccc}
\hline$A^{*}$ & $F$ & $G$ & $H$ & $I$ \\
\hline 0.59 & 0.89 & 3.59 & 1.44 & 0.44 \\
$-14.07^{* * *}$ & $8.18^{* * *}$ & -0.84 & $5.96 * * *$ & $3.13^{* * *}$ \\
0.49 & 0.94 & 0.11 & 0.56 & 0.29 \\
$2.55^{* *}$ & $2.22^{* *}$ & -0.27 & 1.25 & 0.43 \\
-0.03 & 0.72 & -0.11 & 0.34 & -1.45 \\
$2.55 * *$ & $2.21^{* *}$ & -0.27 & 1.23 & 0.43 \\
0.50 & 0.94 & -0.01 & 0.59 & 0.29 \\
$2.55^{* *}$ & $2.22^{* *}$ & -0.27 & 1.25 & 0.43 \\
0.02 & 0.74 & -0.16 & 0.63 & -1.51 \\
$2.54^{* *}$ & $2.21 * *$ & -0.27 & 1.23 & 0.43 \\
\hline
\end{tabular}

* The corresponding alpha coefficient is statistically significant at the $10 \%$ level

** The corresponding alpha coefficient is statistically significant at the $5 \%$ level

$* * *$ The corresponding alpha coefficient is statistically significant at the $1 \%$ level 


\section{Table 5: Peak-End and the Fama-French 5 Factor Model: P25-P1 coefficient absolute values}

This table reports the absolute values of difference in coefficients between P25 containing large capitalisation stocks with large momentum and P1 containing small capitalisation stocks with small momentum. Column A* shows results for the complete sample period (Jul.1963 - Dec.2014), for which the Fama-French 5 factor model risk factors are available. The remaining columns contain results for 11 year sub samples.

\begin{tabular}{|c|c|c|c|c|c|}
\hline & P25-P1 & & & & \\
\hline Panels A to I: Results for portfolios P25-P1 & $A^{*}$ & $F$ & $G$ & $H$ & $I$ \\
\hline 1) PEAK+END alpha & 0.59 & 0.89 & 3.59 & 1.44 & 0.44 \\
\hline 14) FF 5 FACTOR MODEL & 0.49 & 0.94 & 0.11 & 0.56 & 0.29 \\
\hline 15) FF 5 FACTOR MODEL + PEAK & 0.03 & 0.72 & 0.11 & 0.34 & 1.45 \\
\hline 16) FF 5 FACTOR MODEL + END & 0.50 & 0.94 & 0.01 & 0.59 & 0.29 \\
\hline 17) FF 5 FACTOR MODEL + PEAK + END & 0.02 & 0.74 & 0.16 & 0.63 & 1.51 \\
\hline MINIMUM & 0.02 & 0.01 & 0.01 & 0.34 & 0.29 \\
\hline
\end{tabular}

